Info Artikel Diterima Desember 2020

Disetujui Februari 2021

Dipublikasikan April 2021

\title{
STUDI PERTUMBUHAN DAN EVALUASI SISTEM TUMPANGSARI \\ (INTERCROPPING) PADA MELON (Cucumis melo, L) dan CABAI \\ (Capsicum anuum, L)
}

\section{STUDY OF THE GROWTH AND INTERCROPPING EVALUATION OF MELON (Cucumis melo, L) and CHILI (Capsicum anuum, L)}

\author{
Dwi Suci Lestariana1, Shalahuddin Mukti Prabowo² \\ ${ }^{1}$ Program Studi Agroteknologi \\ Fakultas Pertanian Universitas Boyolali \\ ${ }^{2}$ Program Studi Agroteknologi \\ Fakultas Pertanian Universitas Islam Batik Surakarta
}

Email: dwisuci@uby.ac.id

\begin{abstract}
Melons and chilies are horticultural commodities that have high economic value and are in great demand by Indonesians. Klaten Regency, especially in Wedi District, is one of the suppliers of melons in the Central Java Market because it has a large harvest area with an average production of $72.86 \mathrm{KwHa}-1$ with a harvest area of $7 \mathrm{Ha}$ but this is not balanced with high chili production (only 3, $2 \mathrm{KwHa}-1$ with a harvest area of $5 \mathrm{Ha}$ ). This study aims to determine the growth response of horticultural products with high economic value, namely melons and chilies which are cultivated intercropping. This research was conducted in Klaten Regency. The design used was factorial Complete Randomized Block Design (RAKL). The first factor is the chili variety consisting of B1 (red chili pepper) and B2 (red curly chili) and the second factor is the melon variety consisting of M1 (white melon) M2 (red melon). Each treatment was repeated 3 times plus 4 monoculture treatments each for melon and chili as a control. The data obtained were then analyzed descriptively. Based on the growth data of 2 melon varieties and 2 chili varieties in the intercropping and monoculture systems, it can be concluded that red melon has a good growth response tendency in the intercropping system seen from the indicators of plant height $(97.53 \mathrm{~cm})$, leaf area $(1772.67 \mathrm{~cm} 2)$ and biomass weight $(68.86 \mathrm{~g})$, for chili plants that gave the best growth yield tendency was curly chili with leaf area indicators $(523.97 \mathrm{~cm} 2)$ and biomass weight $(10.87 \mathrm{~g})$. For the best potential yield of melons in the intercropping system tends to be obtained in the intercropping pattern of red melon and cayenne pepper with a potential yield of $31.33 \mathrm{~kg} / \mathrm{plot}$, while the best potential yield of chili is obtained in the intercropping system of white melon and cayenne pepper with a potential yield of 4.60/planting plot. The evaluation of intercropping was carried out by measuring the LER, AI, CR, and ESP values with the conclusion that the intercropping system of white melon and red bird's eye chilies had the best potential results compared to the other 3 intercropping treatments, which was indicated by the LER value of 1.21, AI value
\end{abstract}


of chili cayenne is 0.26 (positive) and the ESP value of the white melon and cayenne pepper planting system is 0.62 .

Keywords: chilici, evaluation, melon, horticulture, intercropping

\begin{abstract}
ABSTRAK
Melon dan cabai adalah komoditas hortikultura yang mempunyai nilai ekonomi tinggi dan sangat diminati oleh masyarakt Indonesia. Kabupaten Klaten khususnya di Kecamatan Wedi termasuk pemasok melon di Pasar Jawa Tengah karena mempunyai luasan panen yang besar dengan rata-rata produksi 72,86 KwHa-1 dengan luasan panen $7 \mathrm{Ha}$ akan tetapi hal ini tidak diimbangi dengan produksi cabai yang tinggi (hanya $3,2 \mathrm{Kw} \mathrm{Ha}-1$ dengan luasan panen $5 \mathrm{Ha}$ ). Penelitian ini bertujuan untuk mengetahui respon pertumbuhan produk hortikultura yang bernilai ekonomis tinggi yaitu melon dan cabai yang dibudidayakan secara tumpang sari. Penelitian ini dilaksanakan di Kabupaten Klaten. Rancangan yang digunakan adalah Rancangan Acak Kelompok Lengkap (RAKL) faktorial. Faktor pertama yaitu varietas cabai terdiri dari B1(cabai rawit merah ) dan B2 (cabai merah keriting) dan faktor kedua yaitu varietas melon yang terdiri M1 (melon putih) M2 (melon merah). Tiap perlakuan diulang 3 kali ditambah 4 perlakuan monokultur masing-masing untuk melon dan cabai sebagai kontrol. Data yang didapatkan kemudian dilakukan analisis secara deskriptif.

Berdasarkan data pertumbuhan 2 varietas melon dan 2 varietas cabai pada sistem tumpangsari maupun monokultur dapat disimpulkan bahwa melon merah mempunyai kecenderungan respon pertumbuhan yang baik pada sistem tumpangsari dilihat dari indikator tinggi tanaman $(97,53 \mathrm{~cm})$, luas daun $(1772,67$ $\left.\mathrm{cm}^{2}\right)$ serta bobot biomass $(68,86 \mathrm{~g})$, untuk tanaman cabai yang memberikan kecenderungan hasil pertumbuhan yang terbaik adalah cabai keriting dengan indikator luas daun $\left(523,97 \mathrm{~cm}^{2}\right)$ serta bobot biomass $(10,87 \mathrm{~g})$. Untuk potensi hasil melon terbaik pada sistem tumpangsari cenderung didapatkan pada pola tumpangsari melon merah dan cabai rawit dengan potensi hasil $31,33 \mathrm{~kg} / \mathrm{petak}$ tanam, sedangkan potensi hasil cabai terbaik didapatkan pada sistem tumpangsari melon putih dan cabai rawit dengan potensi hasil 4,60/petak tanam. Evaluasi tumpangsari dilakukan dengan mengukur nilai LER, AI, CR, dan ESP dengan kesimpulan bahwa sistem tumpangsari melon puth dan cabai rawit merah mempunyai potensi hasil paling baik dibandingkan dengan 3 perlakuan tumpangsari lainnya, yang diindikasikan dari nilai LER sebesar 1,21, Nilai AI cabai rawit sebesar 0,26 (positif) dan nilai ESP sistem pertanaman melon merah dan cabai rawit sebesar 0,62 .
\end{abstract}

Kata kunci: cabai, evaluasi, melon, hortikultura, tumpangsari

\title{
PENDAHULUAN
}

Pertanian di Indonesia merupakan sektor penting sebagai penyangga ketahanan pangan nasional. Petani di Indonesia sebagian besar melakukan kegiatan budidaya tanaman pada tanaman pokok seperti padi, jagung, sagu, dan singkong sebagai sumber penghasilan utama, akan tetapi dimusim-musim tertentu 
ada petani yang memilih untuk melakukan budidaya tanaman hortikultura karena dianggap akan meghasilkan keuntungan yang lebih besar.

Kabupaten Klaten sebagai salah satu Kabupaten penyangga pangan di Jawa Tengah mempunyai areal persawahan yang sangat luas jika dibandingkan dengan Kabupaten lainnya di Jawa Tengah, sehingga di Klaten produk hortikultura menjadi komoditas kedua setelah tanaman pangan. Meskipun demikian, petani menilai budidaya produk hortikultura tetap harus mendapatkan perhatian lebih dari segi teknis budidaya sehingga dengan luasan yang tidak begitu besar, produk hortikultura yang dibudidayakan oleh petani mampu bernilai ekonomi tinggi dan menjadi primadona bagi petani. Produk hortikultura yang menjadi primadona bagi petani di Klaten adalah melon dan cabai, karena menurut petani ketika panen berhasil dan harga jual ke dua produk ini baik secara langsung akan berdampak signifikan bagi kehidupan ekonomi petani. Kecamatan Wedi secara geografis berada di dataran rendah, dan merupakan kecamatan penghasil produksi melon tertinggi di Klaten dengan luasan $7 \mathrm{Ha}$ dan rata-rata produksi mencapai $72,86 \mathrm{Kw} \mathrm{Ha}{ }^{-1}$, akan tetapi rendah bagi produksi cabai di mana di Kecamatan Wedi hanya mempunyai 5 Ha luasan panen cabai dengan rata-rata produksi 3,2 $\mathrm{Kw} \mathrm{Ha}{ }^{-1}$ (BPS, 2017).

Petani yang tidak pernah mau rugi, mulai mencoba melakukan tumpangsari atau yang biasa disebut dengan multiple cropping antara melon dan cabai untuk mendapatkan keuntungan yang optimal di tengah keterbatasan luasan lahan yang ada. Pendapat ini pernah diungkapkan oleh Paudel (2016) yang menyatakan tumpangsari merupakan sistem pertanian jangka panjang yang biasa dilakukan oleh petani di daerah marjinal untuk meningkatkan produktivitas lahan karena keterbatasan lahan yang mereka miliki. Herawati (2016) menambahkan sistem tumpangsari dapat menekan biaya produksi bagi petani karena mampu menekan kebutuhan akan tenaga kerja, mengurangi resiko kegagalan panen, dan resiko pasar. Artinya, jika ada satu komoditas pada periode panen mengalami kegagalan panen atau karena faktor harga yang turun atau petani masih mempunyai komoditas lainnya sebagai sumber penghasilan.

Dalam menjalankan budidaya tumpangsari melon dan cabai, petani belum sampai tahap menganalisis dan mengevaluasi efektifitas dari budidaya tanaman secara tumpangsari. Oleh karena itu, pada penelitian ini Peneliti melakukan analisis dan evaluasi hasil kegiatan tumpangsari melon dan cabai. Beberapa parameter tumpangsari yang dianalisis dan dievaluasi antara lain nilai land equivalent ratio (LER), nilai competitive ratio (CR), Agresivitas Index (AI), Relative Yield Ratio (RYT) dan Efisiensi Sistem Penanaman (ESP).

Tujuan penelitian ini antara lain (1) untuk mengkaji respon pertumbuhan melon dan cabai pada pertanaman dengan sistem tumpangsari (2) untuk menganalisis efisiensi pemanfaatan lahan pada sistem monokultur dan tumpangsari antara melon dan cabai (3) untuk mengevaluasi sistem tumpangsari antara melon dan cabai yang banyak dilakukan oleh masyarakat sehingga dapat dirumuskan potensi pengembangan tumpangsari melon dan cabai khususnya di Kabupaten Klaten, Jawa Tengah, (4) menyediakan informasi bagi kelompok tani, akademisi, dan pelaku industri pertanian tentang sistem tumpangsari melon dan cabai. 


\section{BAHAN DAN METODE}

Penelitian ini menggunakan rancangan acak lengkap (RAKL) yang disusun secara faktorial dengan 2 faktor utama yaitu Melon yang terdiri dari 2 taraf yaitu M1 (melon putih) dan M2 (melon merah) faktor kedua yaitu Cabai yang terdiri dari 2 taraf yaitu $\mathrm{C} 1$ (cabai rawit merah) dan $\mathrm{C} 2$ (cabai keriting merah) ditambah dengan 4 perlakuan monokultur, sehingga didapatkan 8 kombinasi perlakuan sebagai berikut:
M1C0 : monokultur melon putih
M2C0 : monokultur melon merah
M0C1 : monokultur cabai rawit merah
M)C2 : monokultur cabai keriting merah
M1C1 : tumpangsari melon putih dan cabai rawit merah
M1C2 : tumpangsari melon putih dan cabai keriting merah
M2C1 : tumpangsari melon merah dan cabai rawit merah
M2C2 : tumpangsari melon merah dan cabai keriting merah

Variabel pertumbuhan dan hasil yang diamati antara lain

1. Tinggi tanaman

Tinggi tanaman diamati setiap minggu sampai tanaman berumur 7 MST dimulai dari pangkal batang sampai titik tumbuh.

2. Luas daun

Luas daun diamati pada saat 7 MST dengan metode gravimetri yang didapatkan dengan rumus $\mathrm{LD}=\frac{\text { BKdauntotal }}{\text { BKdaunsubsampel }}$ Xluasdaunsubsampel

3. Bobot biomass tanaman

Bobot biomass tanaman didapatkan dengan menimbang berat kering seluruh tanaman pada 7 MST dalam satuan gram (g)

4. Potensi berat buah per tanaman

Potensi berat buah per tanaman dilakukan pada saat panen dalam satuan kilogram $(\mathrm{kg})$.

5. Potensi berat buah per petak tanam.

Potensi berat buah per petak tanam dilakukan pada saat panen dalam satuan kilogram $(\mathrm{kg})$. lain:

Variabel evaluasi untuk sistem pertanaman tumpangsari yang diamati antara

6. LER (Land Equivalent Ratio). Parameter ini menggambarkan suatu areal yang dibutuhkan untuk total produksi monokultur yang setara dengan satu hektar produksi tumpangsari.

Nilai LER didapatkan dengan rumus $\frac{Y M i}{Y M j}+\frac{X C i}{X C j}$

(Amanullah et al, 2016).

YMi : hasil tanaman melon yang ditumpangsarikan 
YMj : : hasil tanaman melon yang dimonokulturkan

$\mathrm{XCi} \quad$ : hasil tanaman cabai yang ditumpangsarikan

YCj : hasil tanaman cabai yang dimonokulturkan

7. $\mathrm{CR}$ (Competitive Ratio). CR merupakan rasio kompetisi dalam sistem pertanaman tumpangsari.

Nilai CR didapatkan dengan rumus

CR melon $=\frac{\text { LER melon }}{L E R \text { Cabe }} \times \frac{Z_{\text {pmelon }}}{Z_{\text {pcabe }}}$ dan $C R$ cabe $=\frac{\text { LER cabe }}{L E R \text { melon }} \times \frac{Z_{\text {prabe }}}{Z_{\text {pmelon }}}$

(Aminah et al, 2014).

8. RYT (Relative Yield Total). Parameter ini merupakan penjumlahan dari hasil relatif dari masing-masing tanaman penyusun dalam suatu luasan tertentu.

Nilai RYT didapatkan dari rumus

$$
\mathrm{RY} \text { melon }=\frac{D M Y M i}{D M Y M j} \quad \mathrm{RY} \text { cabai }=\frac{D M Y C i}{D M Y C j} \mathrm{RYT}=\mathrm{RY} \text { melon }+\mathrm{RY}
$$

cabai

(Polakitan, 2013)

DMY Mi : produksi bahan kering melon pada sistem tumpangsari

DMY Mj : produksi bahan kering melon pada sistem monokultur

$D M Y C i \quad$ : produksi bahan kering cabai pada sistem tumpangsari

$D M Y C j \quad$ : produksi bahan kering cabai pada sistem monokultur

9. AI (Agresivity Index). Parameter ini menunjukkan ukuran hubungan kompetisi antara dua tanaman dalam pertanaman tumpangsari.

$\mathrm{AI}_{\text {melon }}=\left(\mathrm{DMYMi} / \mathrm{YMj} \times \mathrm{Z} \mathrm{p}_{\text {melon }}\right)-(\mathrm{DMYCi} / \mathrm{YCj} \times \mathrm{Zp}$ cabai $)$

$\mathrm{AI}_{\text {cabe }}=\left(\mathrm{DYCi} / \mathrm{YCj} \times \mathrm{Zp}_{\text {cabai }}\right)-(\mathrm{DMYMi} / \mathrm{YMj} \times \mathrm{Zp}$ melon $)$

Zp melon : poporsi melon

Zp cabai : proporsi cabai

(Layek et al, 2014) 
10. ESP (Efisiensi Sistem Pertanaman). Parameter ini bertujuan untuk mengetahui pemanfaatan waktu pada sistem tumpangsari.

$\mathrm{ESP}=\frac{Y M i+Y C i}{Y M j+Y C j} \times \frac{T a+T b}{T}$

Ta : total waktu yang dibutuhkan untuk monokultur melon

$\mathrm{Tb}$ : total waktu yang dibutuhkan untuk monokultur cabai

$\mathrm{T}$ : Total waktu

Data hasil pengamatan yang diperoleh kemudian direkapitulasi dan diratarata serta dianalisissecara deskriptif.

\section{HASIL DAN PEMBAHASAN}

\section{Analisis Kesuburan Tanah dalam Petak Percobaan}

Analisis kesuburan tanah dilakukan sebelum pengolahan lahan, dengan cara mengambil sampel tanah di beberapa titik, kemudian dikompositkan dan dilakukan analisis kesuburan tanah di Laboratorium. Hasil yang diperoleh kemudian diintepretasikan sesuai dengan sistem pengharkatan tanah. berikut:

Berdasarkan hasil analisis kesuburan tanah didapatkan data sebagai

Tabel 1. Hasil Analisis Kesuburan Tanah (sebelum tanam)

\begin{tabular}{ccccc}
\hline \hline No. & Analisis & Metode & Hasil & Pengharkatan \\
\hline 1. & $\mathrm{~N}$ total & Kjeldhal & $0,17 \%$ & rendah \\
2. & $\mathrm{P}_{2} \mathrm{O}_{5}$ & Bray II & $14,46 \mathrm{ppm}$ & tinggi \\
3. & $\mathrm{K}_{2} \mathrm{O}$ & Ekstraksi Am. Acetat 1 & 0.34 & rendah \\
& \multicolumn{5}{c}{ pH 7.00 } \\
4. & $\mathrm{C} / \mathrm{N}$ Ratio & Kalkulasi & 7.0 & rendah \\
5. & $\mathrm{pH}$ & Elektrode glass & 6.64 & Agak masam
\end{tabular}

Sumber: Hasil Analisis dari Laboratorium Kimia dan Kesuburan Tanah Universitas Sebelas Maret Surakarta

Pengharkatan: Balitbangtan Kementan (2018)

Berdasarkan hasil analisis kesuburan tanah dapat diintepretasikan bahwa tanah di lahan percobaan memiliki kandungan hara yang cenderung rendah.

\section{Pertumbuhan dan Hasil Melon}

Pertumbuhan dan perkembangbiakan merupakan proses alamiah yang terjadi pada tanaman selama siklus hidupnya yang dipengaruhi oleh faktor internal dan faktor eksternal. Faktor internal yang mempengaruhi pertumbuhan adalah 
sumber genetik sedangkan faktor eksternal yang mempengaruhi pertumbuhan dan perkembangbiakan tanaman antara lain kandungan hara dalam tanah, aerasi dan drainase dalam tanah, serta faktor serangan HPT (hama dan penyakit tanaman).

Hasil analisis pertumbuhan dan produksi pada sistem tumpangsari ataupun secara monokultur adalah sebagai berikut:

Tabel 1. Hasil Pertumbuhan Melon dan Cabai pada Sistem Monokultur dan Tumpangsari

\begin{tabular}{|c|c|c|c|c|c|c|}
\hline \multirow[t]{2}{*}{ Perlakuan } & \multicolumn{2}{|c|}{$\begin{array}{l}\text { Tinggi } \\
\text { Tanaman } \\
\text { (cm) }\end{array}$} & \multicolumn{2}{|c|}{ Luas Daun $\left(\mathrm{cm}^{2}\right)$} & \multicolumn{2}{|c|}{ Bobot Biomass $(\mathrm{g})$} \\
\hline & M & $\mathrm{C}$ & M & $\mathrm{C}$ & M & $\mathrm{C}$ \\
\hline \multirow{2}{*}{ M0C1 } & & 61,3 & & 272,9 & & \\
\hline & 0,00 & 8 & 0,00 & 0 & 0,00 & 8,48 \\
\hline \multirow{2}{*}{ M0C2 } & & 67,2 & & 523,9 & & \\
\hline & 0,00 & 0 & $\begin{array}{c}0,00 \\
1473,3\end{array}$ & 7 & 0,00 & 10,87 \\
\hline \multirow[t]{2}{*}{$\mathrm{M} 1 \mathrm{C} 0$} & 61,16 & 0,00 & 3 & 0,00 & 38,35 & 0,00 \\
\hline & & 65,1 & 1285,3 & 515,7 & & \\
\hline \multirow[t]{2}{*}{$\mathrm{M} 1 \mathrm{C} 1$} & 70,39 & 3 & 3 & 2 & 39,10 & 10,13 \\
\hline & & 61,6 & 1061,6 & 327,0 & & \\
\hline \multirow[t]{2}{*}{ M1C2 } & 63,42 & 7 & 7 & 5 & 36,20 & 6,78 \\
\hline & & & 1752,6 & & & \\
\hline \multirow[t]{2}{*}{$\mathrm{M} 2 \mathrm{C} 0$} & 96,83 & 0,00 & 7 & 0,00 & 66,59 & 0,00 \\
\hline & & 69,2 & 1782,3 & 439,8 & & \\
\hline \multirow[t]{2}{*}{$\mathrm{M} 2 \mathrm{C} 1$} & 97,53 & 2 & 3 & 9 & 68,86 & 6,56 \\
\hline & & 70,5 & 1772,6 & 304,7 & & \\
\hline $\mathrm{M} 2 \mathrm{C} 2$ & 94,89 & 8 & 7 & 4 & 63,87 & 7,03 \\
\hline
\end{tabular}

Sumber: Data Hasil Pengamatan

Tabel 2. Hasil Melon dan Cabai pada Sistem Monokultur dan Tumpangsari

\begin{tabular}{ccccc}
\hline \hline \multirow{2}{*}{ Perlakuan } & \multicolumn{2}{c}{$\begin{array}{c}\text { Bobot buah/tanam } \\
(\mathrm{kg})\end{array}$} & \multicolumn{2}{c}{ Potensi Hasil/ Petak $(\mathrm{kg})$} \\
& 0,00 & 0,00 & 0,00 & $\mathrm{C}$ \\
\hline M0C1 & 0,00 & 0,00 & 0,00 & 8,62 \\
M0C2 & 1,27 & 1,27 & 50,93 & 0,00 \\
M1C0 & 0,51 & 0,51 & 10,20 & 4,60 \\
M1C1 & & & &
\end{tabular}




\begin{tabular}{lllll} 
M1C2 & 0,51 & 0,51 & 10,13 & 2,70 \\
M2C0 & 1,23 & 1,23 & 49,33 & 0,00 \\
M2C1 & 1,55 & 1,55 & 31,00 & 4,54 \\
M2C2 & 1,57 & 1,57 & 31,33 & 2,78 \\
\hline
\end{tabular}

Sumber: Data Hasil Pengamatan.

Respon pertumbuhan melon dan cabai yag terbaik cenderung dihasilkan oleh melon merah baik yang dibudidayaan secara monokultur maupun tumpangsari dan respon pertumbuhan cabai yang terbaik dihasilkan oleh cabai keriting merah baik yang dibudidayakan secara monokulur maupun tumpangsari (Tabel 1). Pada penelitian ini dilihat dari indikator tinggi tanaman pertumbuhan melon putih maupun melon merah cenderung lebih rendah jika dibandingkan dengan pertumbuhan melon pada umumnya seperti hasil penelitian Triadiati et al (2019) di mana pada hasil penelitian tersebut tinggi tanaman melon mencapai lebih dari satu meter. Kandungan hara tanah atau tingkat kesuburan tanah menjadi faktor eksternal yang mempengaruhi pertumbuhan tanaman. Berdasarkan hasil analisis kesuburan tanah menunjukkan bahwa lokasi tempat penelitian mengalami defisiensi hara terutama untuk unsur $\mathrm{N}$ dan $\mathrm{K}$, serta kandungan $\mathrm{C}$ organik (bahan organik) yang cenderung rendah. Hasil penelitian Lestariana dan Aulia (2020) menyatakan bahwa hara $\mathrm{N}$ berperan dalam fase pertumbuhan tanaman terutama pada saat stadia vegetatif, serta penyerapan yang baik oleh tanaman akan membantu pertumbuhan tanaman mulai fase awal sampai saat panen. Respon pertumbuhan terbaik pada melon merah dan cabai keriting baik yang dibudidayakan secara monokultur maupun secara tumpangsari mengindikasikan bahwa akar melon merah dan cabai keriting mampu menyerap hara lebih baik dibandingkan akar melon putih dan cabai rawit merah.

Hasil melon dan cabai merupakan indikator kemampuan tanaman dalam memasuki fase generatif tanaman. Berdasarkan tabel 2 diketahui bahwa melon merah memiliki potensi hasil yang lebih baik daripada melon putih baik yang dibudidayakan secara monokultur maupun tumpangsari, untuk potensi hasil pada cabai menunjukkan bahwa respon kedua jenis cabai terhadap potensi hasil cenderung sama. Hasil tanaman (produksi tanaman) selain dipengaruhi oleh hara $\mathrm{N}$, juga dipengaruhi oleh hara $\mathrm{P}$ dan $\mathrm{K}$, dalam hal ini kemampuan akar melon merah dalam menyerap hara lebih baik dari melon putih sehingga potensi hasil melon putih cenderung rendah.

\section{Evaluasi Tumpangsari}

Evaluasi tumpangsari bertujuan untuk mengetahui tingkat efektivitas dan efisiensi dari sistem pertanaman tumpangsari jika dibandingkan dengan sistem pertanian monokultur. 
Tabel 3. Evaluasi Sistem Tumpangsari Melon dan Cabai pada 2 Varietas yang Berbeda

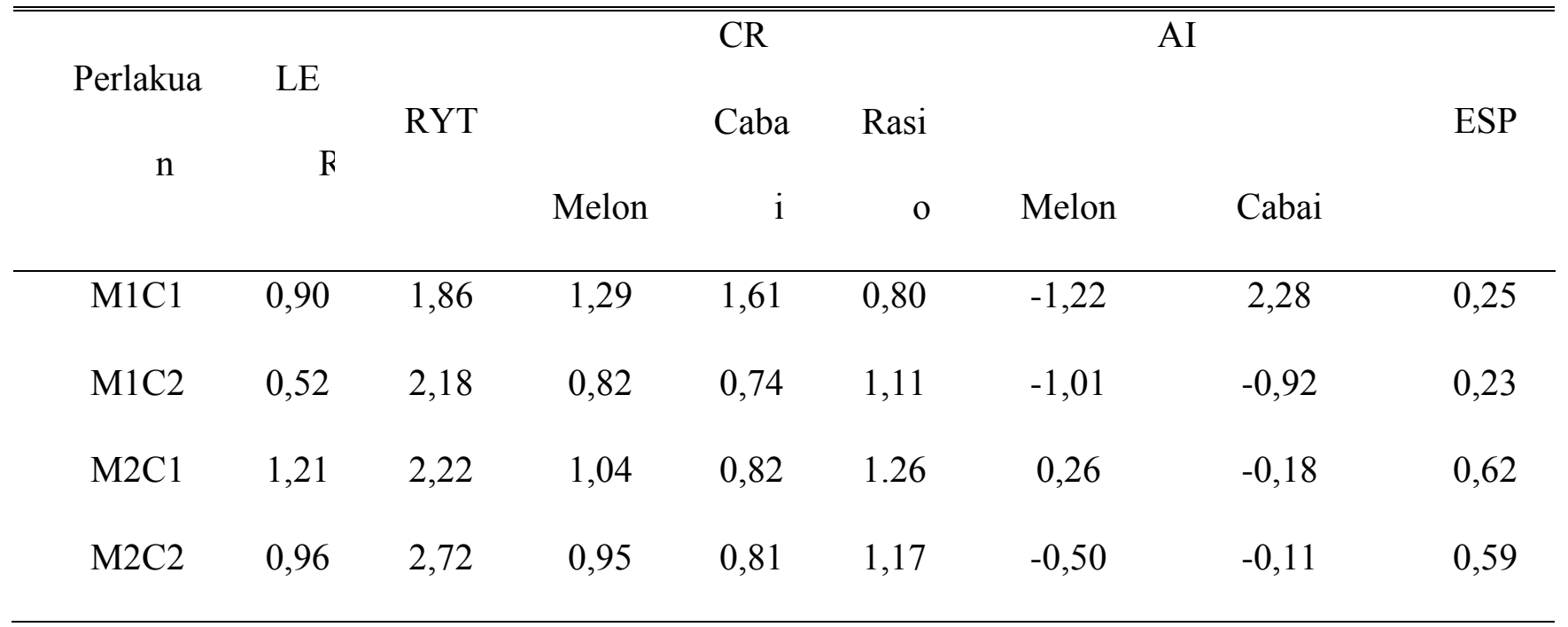

Sumber data: Data Hasil Pengamatan

LER (land equivalent ratio) adalah indikator untuk mengkur tingkat produktivitas lahan pada sistem tumpangsari. Mutmaidah dan Sundari (2017) menjelaskan bahwa jika nilai LER $>1$ maka produktivitas lahan tumpangsari lebih tinggi daripada monokultur. Berdasarkan data pada tabel 3 diketahui bahwa lahan yang digunakan untuk tumpangsari melon merah dan cabai rawit merah lebih produktif daripada ke 3 sistem tumpangsari lainnya.

RYT (Relative Yield Total) adalah indikator untuk mengukur efisiensi pemanfaatan lahan pada sistem tumpangsari. Data pada tabel 3 menunjukkan bahwa nilai RYT dari 4 jenis sistem tumpangsari menunjukkan nilai $>1$, yang berarti sistem tumpangsari melon dengan cabai pada 2 varietas melon dan 2 varietas cabai yang berbeda menguntungkan petani (Polakitan, 2013). Hal ini menunjukkan bahwa total produksi tanaman penyusun adalah tinggi jika dibandingkan ketika budidaya dilaksanakan secara monokultur.

CR (Competitive Ratio) merupakan indikator tingkat persaingan kedua spesies dalam suatu sistem tumpangsari. Apabila nilai rasio kompetisi tinggi maka sistem tumpangsari mampu meningkatkan pertumbuhan, dan apabila rasio kompetisi rendah maka dapat berpotensi untuk menekan pertumbuhan. Tabel 3 menunjukkan hasil bahwa nilai CR tertinggi pada tumpang sari melon dan cabai berturut-turut adalah 1,$26 ; 1,17 ; 1,11 ; 0,80$. tumpangsari antara melon merah dan cabai rawit merah mempunyai nilai CR tertinggi hal ini sejalan dengan parameter hasil (produksi) di mana potensi hasil per petak tanam pada perlakuan ini cenderung tinggi (Tabel 2).

AI (Agresivity Index) merupakan ukuran tingkat kompetisi antara 2 spesies dalam sistem tumpangsari. Nilai AI positif berarti kedua spesies kuat (dominan), nilai AI negatif berarti spesies lemah, dan jika nilai AI 0 artinya kedua spesies sama-sama kompetitif. Tabel 3 menunjukkan bahwa pada perlakuan M1C1 melon putih cenderung lemah daripada cabai rawit merah, pada perlakuan M1C2 baik melon putih ataupun cabai rawit keriting sama-sama lemah, pada 
perlakuan $\mathrm{M} 2 \mathrm{C} 1$ melon merah cenderung dominan daripada cabai rawit merah, dan pada perlakuan $\mathrm{M} 2 \mathrm{C} 2$ baik melon merah dan cabai rawit merah sama-sama lemah dalam berkompetisi.

ESP (Efisiensi Sistem Penanaman) merupakan indikator tingkat efisiensi penggunaan lahan dalam sistem tumpangsari. Nilai ESP tertinggi terdapat pada perlakuan $\mathrm{M} 2 \mathrm{C} 1$ artinya tumpangsari antara melon merah dan cabai rawit merah lebih efisien dari segi waktu jika dibandingkan dengan ketiga sistem tumpangsari lainnya. Perlakuan M1C2 cenderung tidak efisien dari segi waktu pelaksanaan tumpangsari.

\section{KESIMPULAN DAN SARAN}

Kesimpulan yang dapat diambil dari penelitian ini antara lain:

1. Melon merah mempunyai kecenderungan hasil pertumbuhan yang lebih baik dibandingkan dengan melon putih, cabai rawit merah mempunyai kecenderungan hasil pertumbuhan yang lebih baik dibandingkan dengan cabai rawit keriting.

2. Pada sistem tumpangsari melon merah mempunyai potensi hasil produksi yang lebih tinggi dibandingkan melon putih, dan cabai rawit merah mempunyai potensi hasil yang lebih tinggi dibandingkan cabai keriting.

3. Hasil evaluasi beberapa nilai indikator pada tumpangsari menunjukkan bahwa tumpangsari antara melon merah dan cabai rawit merah lebih berpotensi untuk dikembangkan oleh petani.

Saran yang penulis berikan antara lain:

1. Perlunya kedisiplinan petani dalam mengelola lahan pertanian melon dan cabai.

2. Melon dan Cabai merupakan tanaman dalam satu famili yang mempunyai peluang untuk diserang HPT dari jenis yang sama, sehingga petani pelaksana harus bersungguh-sungguh dalam melakukan perawatan tanaman, dimulai pada saat olah lahan sampai dengan panen.

\section{TERIMAKASIH}

Ucapan terimakasih penulisa sampaikan kepada Kementerian Riset Teknologi/ Badan Riset dan Inovasi Nasional yang telah mendanai penelitian ini melalui Hibah Kompetitif Nasional dengan skim Penelitian Dosen Pemula.

\section{DAFTAR PUSTAKA}

Amanullah, DR. (2016). Land equivalent ratio, growth, yield and yield components response of mono-cropped vs. inter-cropped common bean and maize with and without compost application. Agric. Biol. J. North America. 7. 40-49.

Aminah, I. S., Budianta, D., Munandar, M., Perto, Y., \& Sodikin, E. (2014). Tumpangsari jagung (Zea mays L.) dan kedelai (Glycine max L. Merrill) untuk efisiensi penggunaan dan peningkatan produksi lahan pasang surut. Jurnal Tanah dan Iklim 38(2), 119-128. 
Badan Pusat Statistik. 2017. Statistik Hortikultura 2016. Dinas Pertanian dan Perkebunan Provinsi Jawa Tengah.

Herawati, D.T. 2016. Kajian Ekonomi antara Pola Tanam Monokultur dan Tumpangsari Tanaman Jagung, Kubis, dan Bayam. Inovasi Vol $18(1), 66-71$

Layek, J., Shivakumar, B. G., Rana, D. S., Munda, S., Lakshman, K., Das, A., \& Ramkrushna, G. I. (2014). Soybean-cereal intercropping systems as influenced by nitrogen nutrition. Agronomy Journal, 106(6), 19331946.

Lestariana, D. S., \& Aulia, M. P. (2020). RESPON KEDELAI HITAM (Glycine max (L) MERRIL) DENGAN INOKULASI MIKORIZA PADA BERBAGAI TARAF PEMUPUKAN ANORGANIK DI TANAH REGOSOL BOYOLALI. Jurnal Agriovet, 2(1), 17-42.

Mutmaidah, S., \& Sundari, T. (2017). Efisiensi pemanfaatan lahan untuk memaksimalkan pendapatan dengan pola tumpangsari jagung dan kedelai. In Prosiding Seminar Hasil Penelitian Tanaman Aneka Kacang dan Umbi (p. 333).

Paudel, M.N. 2016. Multiple Cropping for Raising Productivity and Farm Income of Small Farmers. Journal of Nepal Agricultural Research Council Vol $2,37-45$.

POLAKITAN, A., Pertanian, B. P. T., \& Kalasey, S. U. J. K. P. (2013). Kajian Produktivitas dan Efisiensi Pola Tanam Kelapa dan Padi Gogo. Buletin Palma, 14 (2), 1-7

Rochayati, S. 2018. Intepretasi Data Hasil Analisis Tanah, Tanamn, dan Pupuk. Balai Penelitian Tanah dan Badan Penelitian dan Pengembangan Pertanian. http://litbangpertanian.go.id 